
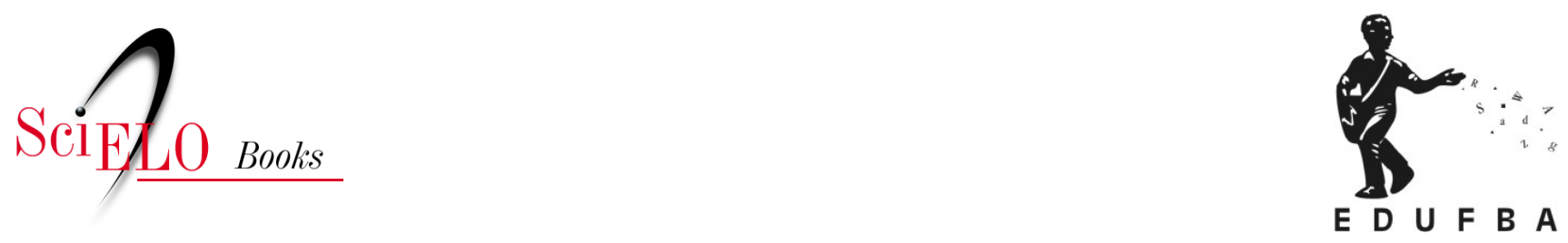

\title{
Confinamento em alto mar de militares da Marinha do Brasil e repercussões na qualidade de vida
}

\author{
Ana Carolina Nascimento de Albuquerque Ramos \\ Paulo Gilvane Lopes Pena
}

\section{SciELO Books / SciELO Livros / SciELO Libros}

RAMOS, A.C.N.A., and PENA, P.G.L. Confinamento em alto mar de militares da Marinha do Brasil e repercussões na qualidade de vida. In: LIMA, M.A.G., FREITAS, M.C.S., PENA, P.G.L., and TRAD, S., orgs. Estudos de saúde, ambiente e trabalho: aspectos socioculturais [online]. Salvador: EDUFBA, 2017, pp. 33-52. ISBN: 978-85-232-1864-5. http://doi.org/10.7476/9788523218645.0003

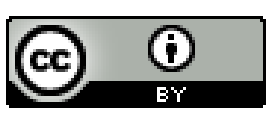

All the contents of this work, except where otherwise noted, is licensed under a Creative Commons Attribution $\underline{4.0 \text { International license. }}$

Todo o conteúdo deste trabalho, exceto quando houver ressalva, é publicado sob a licença $\underline{\text { Creative Commons }}$ Atribição 4.0. 


\title{
Confinamento em alto mar de militares da Marinha do Brasil e repercussões na qualidade de vida
}

\author{
ANA CAROLINA NASCIMENTO DE ALBUQUERQUE RAMOS \\ PAULO GILVANE LOPES PENA
}

\section{Introdução}

Na atualidade, o "mundo do trabalho" configura-se como um contexto de inúmeras transformações sociais, políticas e econômicas que, inevitavelmente, produzem reflexos no comportamento e relacionamento humano. No caso da Marinha do Brasil, instituição das Forças Armadas, além das peculiaridades da vida militar, a atividade profissional requer longos períodos em alto mar e o distanciamento da convivência social mais ampla, revelando um duplo desafio à promoção da qualidade de vida e saúde desses trabalhadores. Na literatura nacional, apesar de pouco extensa, as pesquisas revelam a importância do isolamento marítimo para o desenvolvimento de doenças e consequentes dispensas temporárias durante as atividades (SILVA; SANTANA, 2004), assim como enfermidades relacionadas à cultura institucional. (HALPERN; LEITE, 2011, 2013a, 2013b, 2014) 
O trabalho na Marinha tem suas especificidades históricas seculares diante da instituição militar. Sabe-se que o surgimento da Marinha Brasileira remonta à época do descobrimento do Brasil quando portugueses e franceses disputavam o poder das terras brasileiras. Nesse combate, indígenas se uniram aos portugueses, reforçando a esquadra com embarcações a remo. Além de ter sido a primeira defesa organizada contra uma invasão ao território brasileiro, o fato caracterizou-se como o nascedouro da Marinha do Brasil. (MARINHA DO BRASIL, 2013)

Desde então, tem como principal atividade a defesa da pátria e a garantia dos poderes constitucionais (BRASIL, 2005) organizada com base em uma hierarquia e disciplina, cujas bases ideológicas se confundem com a sua origem. A tripulação das embarcações realiza diversas operações de treinamento pessoal e exercícios no mar, existindo as operações de caráter real, como socorro e salvamento, patrulha naval, operações de paz da Organização das Nações Unidas (ONU), ações humanitárias, dentre outras.

Tais atividades requerem períodos de afastamento da vida social no continente, seja dos familiares, dos amigos ou de outras atividades como lazer e cultura. Quando o profissional parte para as operações no mar, passando dias e até meses afastando-se de outros ambientes sociais, permanece em uma situação de confinamento coletivo em alto mar. Cabe destacar que o confinamento a que nos referimos nesse estudo não se refere ao espaço da embarcação, mas trata-se do ambiente organizacional onde os trabalhadores levam uma vida fechada, sem acesso a outros ambientes sociais por um determinado período.

Para Goffman (1987), ambientes organizacionais nesses moldes, nos quais os trabalhadores levam uma vida fechada, com períodos prolongados de afastamento do resto da sociedade, podem induzir a um estado social de "destreinamento", quando os indivíduos apresentam um sentimento de "perda" dos papéis sociais em "terra”. A repercussão dessa situação na noção de qualidade de vida desses atores sociais, que é pulverizada no imaginário social como um objetivo a ser alcançado tanto a nível individual quanto organizacional, adquire contornos específicos em cada ambiente de trabalho, em função dos signos e significados compartilhados por cada cultura. Para Limongi-França (2004), a qualidade de vida no trabalho na sociedade pós-industrial envolve elementos como os vínculos e estrutura da vida pessoal, fatores socioeconômicos, metas empresarias e pressões or- 
ganizacionais. Já Minayo, Hartz e Buss (2000, p. 9) abordam a qualidade de vida numa visão mais ampla, menos economicista, acrescentando que "[...] em todas as sondagens feitas sobre qualidade de vida, valores não materiais, como amor, liberdade, solidariedade e inserção social, realização pessoal e felicidade, compõem sua concepção".

Na Marinha, as operações no mar, mesmo em tempos de paz, são consideradas um exercício de operação de guerra e não é permitida a tripulação o uso de aparelhos de telefonia móvel, mesmo que o navio esteja navegando próximo à costa e haja sinal para a comunicação. Esse uso é permitido somente ao comandante do navio, que pode antecipar a presença de "forças inimigas" e desenvolver planos de contingências para eliminar estas ameaças. Alguns navios da Marinha do Brasil possuem uma rede de comunicações que funcionam através do satélite e se limitam ao recebimento e envio de mensagens institucionais e telefonemas emergenciais. Todos esses cuidados fazem parte das orientações do Guia de Guerra Naval (2000) que determina a segurança das informações, para que a operação consiga êxito e o navio em guerra não seja detectado e atingido por seus inimigos.

Salienta-se que, no período de formação, os militares passam também por certo distanciamento da sociedade, pois tanto na Escola Naval, instituição formadora dos oficiais da Marinha, quanto nas Escolas de Aprendizes de Marinheiros, instituição formadora do corpo de praças da armada, os alunos permanecem em regime de internato durante toda a semana, sendo liberados somente aos finais de semana para realizar as atividades de lazer e ver a família. Como analisa Lins (2012, p. 20):

Os jovens entravam ainda muito cedo e ficavam muitas vezes longe de suas famílias, com rígidas regras disciplinares a serem cumpridas por todos em longos períodos de afastamento de uma vida externa, seja pelo confinamento no quartel, seja pelas viagens de instrução em que o oceano era único diálogo com o mundo externo. Pode-se dizer que viviam uma situação de expropriação de sua autonomia e de suas relações sociais mais amplas.

Nesse sentido, o estudo da qualidade de vida na marinha está condicionado às noções de distanciamento, isolamento e internamento tanto em navios como em terra. Essa pertinência estrutural se adiciona às características do modo de organização militar citados, como hierarquia e disciplina. O trabalho exerce uma posição central, e, dialeticamente, o trabalhador olha 
para “[...] o mundo a partir de uma janela, onde a profissão cria as cores e as nuances da paisagem da casa, do bairro, da vida associativa e dos projetos do futuro". (MINAYO; SOUZA, 2003, p. 293)

Portanto, o fio condutor da presente reflexão expressa a necessidade de se pensar e repensar uma proposta de intervenção que corrobore com a manutenção/promoção da saúde e qualidade de vida do trabalhador, sem deixar de considerar as especificidades dos sujeitos estudados, composta por militares da Marinha do Brasil. Procuramos compreender as repercussões na qualidade de vida dos militares e como esse tipo de trabalhador se configura no ambiente de trabalho e fora dele. A vida social aqui estudada é a maneira que o indivíduo interage com a sociedade, através das suas relações sociais e atividades desenvolvidas.

\section{Metodologia}

Utilizando técnicas da abordagem qualitativa, a investigação buscou descrever a complexidade do problema, especialmente na esfera subjetiva, apreendendo as características, propriedades ou relações existentes na realidade pesquisada, tendo como referência duas categorias: o isolamento e a reserva/aposentadoria militar. A produção dos dados se deu a partir da realização de entrevistas e da pesquisa documental na divisão de pessoal dos próprios navios. O conteúdo acumulado no diário de campo, assim como, o material produzido nas entrevistas, constituíram a base empírica da pesquisa. No processo de análise, sistematização e interpretação dos dados empíricos, o foco foi a especificidade do caso concreto, quanto ao caráter universal da sua manifestação, visando um processo de refinamento de problemas e conceitos.

Para as entrevistas, foi utilizado um roteiro semiestruturado (MINAYO, 2010) dividido em quatro partes: (a) informações pessoais e profissionais; (b) perfil socioeconômico; (c) aspectos relacionados à satisfação no trabalho; (d) aspectos relacionados à saúde e vida social. Por razões estratégicas, aspectos ligados ao uso e abuso de drogas lícitas ou ilícitas não foram analisadas, pois tal problemática demandaria novas modalidades de abordagens dos sujeitos não exploradas nesta fase do estudo. As entrevistas foram gravadas em aparelho e transcritas na íntegra após o consentimento do entrevistado.

Para compreender os impactos do confinamento na vida social, as interpretações levaram em consideração os eixos temáticos selecionados 
para a discussão, que, por sua vez, derivaram de recortes das narrativas sobre o confinamento em alto mar, as relações interpessoais e a vida social. Procurou-se em todo o processo de análise do conteúdo coletado em campo integrar texto e contexto, situando a narrativa dos informantes a partir do lugar de onde falavam. Além disso, foi adotada uma perspectiva intertextual que permitiu confrontar concepções e interesses dos diferentes atores abordados, delineando pontos de convergências ou de conflitos entre eles. (MINAYO, 2008, 2010)

Participaram das entrevistas dezoito tripulantes de três navios, contemplando todos os tipos de navios do Comando do Segundo Distrito Naval. Foram incluídos na pesquisa os militares envolvidos com atividades operativas e manobras de navegação e que representavam os diferentes níveis hierárquicos.

A pesquisa teve início após a autorização do Comando do Segundo Distrito Naval e a aprovação do Comitê de Ética em Pesquisa da Faculdade de Medicina da Bahia ( $\mathrm{n}$ - 840.619). Foi garantido o sigilo absoluto aos entrevistados, identificando-os através de números. As diretrizes e normas regulamentadoras de pesquisa envolvendo seres humanos do Conselho Nacional de Saúde (CNS) na sua Resolução 466/12 foram respeitadas, e, todos os entrevistados concordaram com a entrevista, assinando o termo de consentimento livre e esclarecido.

\section{Resultados e discussão}

A análise qualitativa do estudo foi composta por nove sargentos, três cabos e três oficiais. Quanto à especialidade, dos três oficiais, temos dois especializados em máquinas e um armamentista. Em relação aos praças, temos dois armamentistas, dois escreventes, dois especializados em manobras e reparos, dois em motores, um em eletrônica, um operador de radar, um enfermeiro e um arrumador.

Em relação ao nível de instrução dos militares participantes da pesquisa: 12 militares da amostra qualitativa concluíram o ensino médio e apenas três militares apresentaram o ensino superior completo. Dos que concluíram o ensino superior, todos são oficiais que se formaram na própria Força. No que tange a idade, os militares entrevistados apresentaram de 24 a 46 anos. Em relação ao tempo de carreira possuem de 6 a 29 anos e quanto ao tempo de embarque possuem de 2 a 23 anos. 
Paradoxalmente, esses militares que servem embarcados nos meios operativos $^{1}$ são os que têm maior dificuldade no acesso aos programas nas áreas de qualidade de vida e saúde da marinha, seja por estarem com frequência em comissões quando estes projetos se realizam ou quando em terra, pela intensa rotina de preparação do navio para habilitá-lo à comissão seguinte.

As categorias analíticas centrais identificadas neste estudo se constituíram na modalidade de trabalho confinado na marinha e na perda da identidade social do marinheiro com a sua aposentadoria. Estas foram identificadas como condições essenciais para reflexão na qualidade de vida durante a vida laboral e, por decorrência, na preocupação com a vida enquanto aposentado.

O confinamento em alto mar e o "destreinamento" da vida familiar: instituição total não totalitária

Quando pedimos para os militares descreverem o que pensam sobre o confinamento a maioria apresentou um sentimento de perda de tempo e de vida e caracterizou como "ruim", "complicado", mesmo que "adaptável”: "Eu estou há 23 anos confinado praticamente... Eu já acostumei... É uma vida... É muito difícil, penso que perdi muito tempo...”. (Militar 3, Navio 2) Outro fato observado é a perda da noção do tempo quando embarcados:

Se eu the disser que já passei dois, três dias sem saber o que é a luz do sol, talvez você não acredite, mas é possível, você passar dias sem saber o que é a luz do sol. Você fica dentro do navio e o navio tem tudo, você não precisa sair pra nada. Em navios grandes acontece de vocêficar dias sem ver a luz do sol. Você tem sua rotina, seu serviço, volta pro seu alojamento e fica sem ver a luz do sol... (Militar 1, Navio 2)

Outra afirmação muito citada é o fato de o tempo demorar a passar ou o dia parecer mais longo como comenta um militar: "Cada dia parece uma semana... A questão da ausência da família é ruim”. (Militar 2, Navio 3)

Além da noção do tempo ser distinta a dos trabalhadores comuns, sentem uma grande necessidade de serem mais presentes na vida da família quando estão em terra. Possuem o desejo de realizar várias atividades e compensar o tempo perdido, como podemos compreender nas falas a seguir:

1 Entende-se como meios operativos, os navios, submarinos e aeronaves que executam as operações navais de guerra da Marinha do Brasil. 
O confinamento é bom e ruim. Quando está confinado você dá mais valor ao que está lá fora e quando você está lá fora, você dá valor ao que está aqui dentro. Às vezes no mar, eu fico ali na polpa do navio do nada, olhando pro mar é é bom pra refletir e não tem ninguém ali do lado. E quando chego de viagem, pego minha esposa, a gente sai pra jantar, a gente vai passear e não vira rotina. Acaba sendo uma coisa legal sabe... (Militar 2, Navio 1)

Quando estou em casa eu procuro dar atenção, sair, conversar pra compensar... Em viagem a gente não pode ligar, tem comissão operativa que não pode ligar e também tem dias que não tem sinal o telefone. No dia do meu aniversário minha avó morreu e eu estava no mar também... Foi bom até eu não saber, pois é complicado... No mar a gente não tem o que fazer... Às vezes é bom a gente nem saber. (Militar 2, Navio 2)

O confinamento rompe periodicamente laços sociais de afeto que podem repercutir na dinâmica psíquica no cotidiano do trabalho. Uma das principais dificuldades enfrentadas durante as comissões que apareceram nos discursos dos militares é a ausência da família. Muitos servidores da marinha narraram com tristeza à perda de eventos familiares e sociais importantes:

A minha ultima filha eu não vi nascer. Uma fez 18 anos eu estava viajando, a mais velha fez 15 anos e eu não estava em casa, a outra fez 15 anos dois anos atrás e eu não estava em casa. Hoje elas entendem, mas quando eram crianças não entendiam. (Militar 2, Navio 2)

Meus filhos são pequenos ainda. Eles não têm muito entendimento acerca do meu trabalho. A minha esposa o que ela mais reclama é da inconstância de rotina e das viagens, que apesar de dar o suporte financeiro, têm o afastamento de casa, que sempre causa transtorno. (Militar 1, Navio 1)

Os militares entrevistados afirmaram que o relacionamento no navio “é muito bom”, porém alguns apontaram que durante o período de confinamento pode haver mudança no comportamento dos militares devido o aumento do ritmo de trabalho. Como podemos verificar na narração a seguir:

Dentro do navio nós temos uma família. No mar o humor cai um pouco... Às vezes uma brincadeira que vocêfaz no porto, no mar você não pode... Até porque no mar tem mais exigência. A escala é mais apertada... todo mundo a bordo suja-se mais e tem que limpar mais...e não pode jogar no mar, daí acumula...são muitas exigências. (Militar 5, Navio 2) 
Para Salles e Costa (2013) o trabalho em um ambiente confinado é compreendido pelos sujeitos como fonte de superação de desafios diários, tanto no que se refere à própria atividade quanto à rotina de isolamento pela qual eles passam. Dessa forma, percebemos que o trabalho confinado pode influenciar no comportamento e relacionamento da tripulação. Essa convivência, no ambiente confinado, sob o ponto de vista da peculiaridade e da temporalidade remete ao conceito de instituição total adotado por Goffman (1987, p. 11-16), a saber:

Uma instituição total pode ser definida como um local de residência e trabalho onde um grande número de indivíduos com situação semelhante, separados da sociedade mais ampla por considerável período de tempo, levam uma vida fechada e formalmente administrada. [...] Seu fechamento ou seu caráter total é simbolizado pela barreira à relação social com o mundo externo e por proibições à saída que muitas vezes estão incluídas no esquema físico - por exemplo, portas fechadas, paredes altas, arame farpado, fossos, água, florestas ou pântanos.

Goffman (1987), em seu estudo, relacionou as instituições totais em grupos distintos, tais como instituições que cuidam de pessoas incapazes, penitenciárias ou campos de concentração, pessoas que realizam alguma tarefa de trabalho em locais como quartéis, navios, escolas internas e, por último, locais de formação para religiosos. A partir dessa caracterização observa-se que o trabalho dos militares embarcados pode se inserir na noção de instituição total, já que o trabalho é desenvolvido em um todo ambiental, psíquico, social e cultural dentro de um navio, sem acesso ao mundo externo após o período trabalhado.

Esse sistema fechado detém o controle total da vida de seus membros durante o período de permanência nos mesmos, ou seja, nesses ambientes todos os aspectos da vida são desenvolvidos em um único local e submetidos a uma única autoridade. Não obstante, cada momento da vida diária é realizado em companhia de um grupo de pessoas e todas as atividades cotidianas obedecem a horários pré-determinados e a um sistema de regras. (LEITE, 2009) No caso da Marinha do Brasil, o controle total é exercido pela rotina laboral do navio, onde os toques dos apitos no fonoclama ${ }^{2}$ sinalizam a hora

2 Fonoclama é um equipamento de amplificação e distribuição do som utilizado na Marinha do Brasil, destinado a transmitir ordens verbais a bordo ou em terra. É também conhecido como "boca de ferro". 
de acordar (alvorada), os horários das refeições, as rendições de serviço, os exercícios reais e simulados no mar e os avisos de "reunir” para a tripulação receber as ordens do dia pelo comandante do navio. Toda essa rotina é submetida à observância e o acatamento integral das leis, regulamentos, normas e disposições que fundamentam o organismo militar. Esse aspecto é bem conduzido por Leite (2009, p. 104), quando sinaliza:

O obstáculo que as instituições totais colocam entre os homens que habitam os seus espaços e o mundo externo assinala um primeiro corte que diferencia esse espaço institucional dos demais. Na vida civil em geral, tanto as rotinas diárias quanto os ciclos de vida não se tornam impeditivos para que um papel que o trabalhador desempenhe não obstrua sua efetividade e suas ligações em outro. No entanto nas instituições totais, a separação entre os dois mundos perturba a sequência de papéis, pois essa situação pode perdurar por muitos anos. Mesmo quando retorne ao mundo civil e restabeleça alguns destes papéis, muitas dessas perdas, por vezes, são irrecuperáveis.

Deste modo, percebemos que esses trabalhadores vivem em um estado de vigilância constante durante as viagens, pois estão mergulhados no ambiente de trabalho, mesmo no período de descanso. Pode-se dizer que o confinamento em alto mar provoca esse efeito totalizante descrito por Goffman (1987), diante da distância da família, somados à ausência de um convívio social externo e uma rotina rígida formalmente administrada.

Dos 15 militares entrevistados, somente quatro disseram possuir amigos fora do ambiente de marinha, justamente os que têm menos tempo de carreira. Esse fato desvela uma lógica interna do grupo em que a rotina em uma instituição total dificulta a manutenção dos relacionamentos externos a esse meio, como afirma o militar:

Tenho poucos amigos fora do ambiente de marinha... O militar se socializa com quem está ao lado dele. Nenhum professor fica trancado 20 dias dentro de uma escola, o militar da marinha fica no navio... Às vezes precisa dividir uma pasta de dente... Se ele fizer um churrasco ele vai chamar quem? A pessoa que ele conversou 20 minutos na lanchonete ou o amigo da marinha...? Claro que é o amigo da marinha. (Militar 3, Navio 1) 
É possível notar claramente nas falas o afastamento dos amigos de infância e o sofrimento gerado por essas perdas.

Eu só tenho meus amigos aqui no navio. Vida social é uma coisa difícil de lidar. A vinte e poucos anos atrás que eu entrei na marinha eu tinha um monte de amigos. Hoje quando eu vou de férias pra minha cidade natal, Fortaleza, todo mundo que era meus amigos não são mais. O cara nem vai mais lá em casa, a gente fica lá um tempão, o cara não aparece, perde o contato... Quando eu servia aqui como marinheiro eu tinha um monte de amigos paisanos, mas perdi o contato. (Militar 2, Navio 2)

Um fato importante de se destacar é que em distritos navais fora da cidade do Rio de Janeiro, os militares podem de acordo com os critérios de elegibilidade e disponibilidade, residirem em Próprio Nacional Residencial (PNR) nas vilas navais. Sendo assim, o militar sai de sua organização militar no final do horário de expediente e vai para sua casa localizada muitas vezes dentro dos muros da própria base militar. Deste modo, esses trabalhadores não conseguem sair do ambiente de trabalho nem mesmo em seu descanso.

Vida social a gente tem que ter amigos, principalmente de infância, a gente tem que ter proximidade de parentes, a gente não tem... Moro na vila, a maioria dos amigos são colegas de trabalho, a maioria dos amigos da minha esposa, são as esposas dos meus colegas de trabalho, mas é diferente de uma amizade que fazemos num bairro onde nascemos... Hoje a minha vida social é restrita a família. (Militar 5, Navio 2)

A convivência dos marinheiros muitas vezes ultrapassa a fronteira do mar, uma vez que penetra na intimidade da vida privada, no período do descanso em casa. Castro (2007) afirma em seu estudo sobre os militares que a interação social é endógena e estimulada formalmente pela instituição através da organização de eventos de confraternizações e pelos próprios militares ou familiares.

Portanto, aspectos sobre as repercussões na vida social resultantes da organização do trabalho de pessoas isoladas em embarcações foram avaliados nessa investigação. São exemplos: os afastamentos prolongados do convívio com os familiares devido às viagens operativas, às ausências em eventos sociais domésticos simbolicamente importantes, bem como a escassa comunicação com o meio social mais amplo repercutindo na dificuldade em manter amigos de infância ou mesmo na aproximação com pessoas 
que não fazem parte do ambiente de marinha, dentre outros. Trata-se de condições não estranhas aos marinheiros, apresentadas como pressupostos conhecidos e compreendidos por eles, como expressa o Militar 2, Navio 2: “... eu atribuo isso à rotina do trabalho de um navio, pois é uma rotina imprevisível”. Tais características intrínsecas e incontornáveis no cotidiano dos militares embarcados, mesmo aceita por eles, necessitam de estratégias de superação para reduzir repercussões negativas na qualidade de vida.

Os embarcados vivenciam assim uma instituição total, mas diferentemente de um manicômio, estruturado em práticas de exclusão social intencional e governados por métodos perversos impostos aos sujeitos doentes, não há totalitarismo na gestão e na autoridade imposta ao comportamento dos indivíduos. O distanciamento representa condição natural do trabalho no mar e o isolamento é justificável como método de guerra, com função maior de defesa da pátria, no qual os marinheiros aderem, defendem também com valores constitutivos no modo de trabalho. Nesse caso, não há rupturas com o princípio da transparência e com o direito de saber. Com isso, entende-se que a natureza da organização do trabalho verificada neste estudo desvela uma instituição total, porém não totalitária. Tal condição, embora ainda provoque repercussões na qualidade de vida desses militares, atenua o processo de trabalho isolado dos embarcados.

Logo, nota-se que a forma de se viver na marinha e fora dela marca a diferença entre esses militares e os demais trabalhadores que não exercem sua atividade laborativa no regime de confinamento, dentro de uma instituição total, porém não totalitária. Essa peculiaridade colabora para a construção de uma identidade social própria e uma ambivalência dos papéis desempenhados em cada momento da vida.

\section{A perda da identidade social com a aposentadoria: "destreinamento" da vida em sociedade}

O efeito "destreinamento" da vida em sociedade resultante de uma vida em instituição totalizante foi descrito por Goffman (1987). Trata-se do fenômeno dos “institucionalizados” em que a perda do convívio social exclui possibilidades de retorno à sociedade após afastamento da instituição. $\mathrm{Na}$ marinha, esse fenômeno tem levado a preocupação dos Núcleos de Assistência Integrada com a passagem dos militares para a reserva remunera- 
da. As diretrizes da Política de Assistência Social das Forças Armadas e os programas e normas contidos na publicação da Diretoria-Geral do Pessoal da Marinha - DGPM-501 ( 5 a Revisão) ${ }^{3}$ orientam para a implementação de projetos voltados para esse público alvo. Os projetos buscam minimizar os impactos ocasionados pela alteração do estilo de vida por conta da reserva/ aposentadoria, através de atividades de cunho socioeducativo e reflexivo.

Além disso, a Diretoria de Assistência Social da Marinha (DASM) incentiva à promoção de projetos voltados aos militares que já estão na reserva/aposentadoria, com a intenção de fazê-los se sentir vinculados a um grupo. Esses projetos se operacionalizam através de atividades socioeducativas, culturais e encontros anuais em organizações militares da Marinha de todo o Brasil. (BRASIL, 2010)

Percebe-se que as características encontradas em um grupo de militares são diferentes das atribuídas a outros grupos. Na psicologia social esse fenômeno é chamado de "Identidade Social". Em um estudo pioneiro sobre essa temática Tajfel (1982, p. 292) afirma que "a identidade social é parte do autoconceito do indivíduo que se deriva do conhecimento de seu pertencimento a um grupo social, ou grupos, com o significado valorativo e emocional associado a este pertencimento”. Um estudo mais recente de Vala (1997, p. 10) informa que:

A identidade social pode ser concebida como decorrendo da resposta que os indivíduos se dão à interrogação seguinte: "Quem sou eu?’ [...] e é provável que parte da resposta a esta questão venha da associação entre $\mathrm{o}$ eu e diversas categorias sociais [...] Contudo, uma vez associado o eu à pertença a uma categoria ou grupo social, os indivíduos levantam uma nova questão: $\mathrm{O}$ que significa pertencer a este grupo?

Sabemos que nas diversas organizações militares existentes, criam-se vínculos, desenvolvem-se afetos, moldam-se hábitos, costumes peculiares e dialetos próprios, que dificilmente são esquecidos na vida fora da caserna. Ao narrar sobre as relações de amizade, um militar afirma que possui somente um amigo fora do ambiente de marinha, contudo, ao descrever esse relacionamento ele

3 Publicação que rege a intervenção dos profissionais que compõem os Núcleos de Assistência Integrada ao Pessoal da Marinha. Este serviço tem por objetivo atender as demandas dos militares da ativa, servidores civis e seus dependentes nas áreas de Serviço Social, Psicologia e Direito, bem como tem por proposta desenvolver atividades integradas a estas disciplinas. 
conta que esse único amigo fazia parte da instituição, contudo foi reformado ${ }^{4}$ por causa de um problema de saúde. Nessa fala, ele toca em um ponto crucial dos impactos que essa condição pode proporcionar aos militares que deixam a farda por algum motivo, a sensação de perda da identidade. Vejamos:

Eu tenho um amigo no Rio que era da marinha também e teve uns problemas e saiu... Quando a gente servia na fragata, nós trabalhávamos com solvente e não tinha o cuidado de colocar os EPIs e ele ficou com leucemia. E ele ficou avariado, metade do corpo dele ficou paralisado. Amigo mesmo, ele é o único que eu considero. Ele é o único amigo que a gente está sempre se falando. São diversos fatores daquele que trabalha embarcado. Um deles é a perda da identidade. Pois o meio fica diferente quando a gente se afasta... Até hoje esse meu amigo continua conversando sobre os navios... Um dia ele me ligou chorando porque ele ficou sabendo que a Fragata Defensora iria dar baixa... A gente fica deslocadofora desse ambiente. (Militar 2, Navio 2)

Se a aposentadoria pode proporcionar a sensação de perda da identidade social para todos os tipos de trabalhadores, imaginemos os militares que prestam suas atividades laborativas em instituições totais não totalitárias e construíram suas relações sociais dentro dos muros de um quartel ou de um navio.

Na Marinha do Brasil, as manifestações essenciais do valor militar, como a defesa da pátria com o sacrifício da própria vida, estabelece uma idealização do servidor como um herói e essa representação se articula com os objetivos da instituição, como se estabelecesse uma única identidade. $\mathrm{O}$ sentimento de orgulho tem como ideia central uma representação que une esses trabalhadores. Todos estão juntos na mesma faina, no mesmo barco e apesar de todo cansaço, do esforço, do confinamento, das condições e jornada de trabalho conseguem alcançar o objetivo comum.

Estas maneiras de proceder coletivamente em meio às adversidades, podem lhes exigir criatividade, iniciativa e companheirismo e se caracterizar como fontes de prazer. A fala de um militar sobre a vida social restrita à marinha revela a preocupação dele com o período da reserva: ${ }^{5}$

4 A reforma é aplicada com base na condição de saúde do militar-Lei n 6880/80, Art. 104 a 114. Os militares reformados estão dispensados, definitivamente, da prestação de serviço na ativa, mas continuam a perceber remuneração da União.

5 A reserva na marinha é o conjunto dos militares da reserva remunerada e de cidadãos que cumpriram, na marinha, os requisitos legais do serviço militar e os que deles foram dispensados, estando ainda sujeitos a convocações ou mobilizações, de acordo com a Lei nº 6880/80. 
Eu acho que a única característica diferente do militar da marinha é que a vida social se limita às pessoas da marinha, talvez seja mais dificil ir para a reserva, pois você retoma uma vida social mais aberta. Como militar e devido ao confinamento dos navios e as Forças Armadas terem o seu linguajar próprio, o seu cotidiano próprio e a forma de viver próprias, a sua vida social acaba se limitando a $80 \%$ ser dentro do convívio de marinha, porque seus amigos onde estão? Dentro da marinha... As pessoas que você pode conversar estão aonde? Dentro da marinha... E você terá dificuldades com certeza na reserva, pois você acaba se afastando dessas pessoas e precisa adquirir hábitos sociais diferentes com pessoas que jamais vão entender o confinamento dentro de um quarto 3x3. (Militar 3 , Navio 1)

Além da perda da identidade, materializada na Marinha do Brasil pelo status social a que o trabalho militar proporcionava, somado ao distanciamento da rede social do trabalho, a aposentadoria no imaginário social muitas vezes é associada a um emaranhado de preconceitos e estigmas sociais, pois é por meio do trabalho que as pessoas buscam saciar suas necessidades básicas e motivacionais. Como cita Zanelli e Silva (2008 apud ZANELLI; SILVA; SOARES, 2010, p. 22):

Em que pesem as mazelas e metamorfoses processadas na atualidade, o trabalho ocupa um inegável e largo espaço na constituição da existência humana. Insere-se entre as atividades mais importantes, constituindo fonte relevante de significados na constituição da vida humana associada. A ocupação de um ser humano, expressa por meio de suas atividades diárias, ao satisfazerem suas necessidades básicas e motivacionais, compõe elemento central do seu autoconceito, que se torna vital à construção de sua autoestima.

Nota-se que o isolamento em relação à vida civil aumenta à medida de que a prática profissional se torna mais operativa e a perda do vínculo profissional pode influenciar na identidade pessoal, uma vez que a aposentadoria acarreta modificações nas relações instituídas entre indivíduo e a sociedade. Corroborando com este pressuposto, Rodrigues e colaboradores (2005) argumentam que além desses comprometimentos, a aposentadoria pode representar perdas materiais, psicológicas e sociais. Portanto, diante destas configurações, cabe refletir sobre a chegada à aposentadoria para esse grupo de militares que exercem sua atividade em regime de confinamento em navios, pois os mesmos poderão enfrentar diferentes realidades nesta fase da vida. 
A imagem que o militar faz de si, a construção da sua identidade, é perpassada por um processo a que nos referimos simbolicamente de "tirar a farda”. O simbolismo do uniforme que este militar deixará de usar faz com que ele se sinta estranho a esse espaço social, tendo dificuldade de se adaptar à nova rotina e à dinâmica familiar, muitas vezes preterida em função das exigências afetas ao trabalho. Nesse sentido, a aposentadoria pode representar um desafio ainda maior para esta classe de trabalhadores, servidores da pátria e também para a sua família, por ser um momento de profundas mudanças, que requer a construção de novos caminhos pessoais e profissionais.

Um militar quando se referiu à educação dos filhos narrou que sente falta de estar perto "para dar uma instrução necessária, para dar uma correção". (Militar 4, Navio 1) Fazendo uma analogia aos trabalhadores offshore, o estudo de Salles e Costa (2013, p. 238) afirma que: "nos períodos de folga do trabalhador, o tempo de sua família é regido por horários que não são compartilhados com ele. Além disso, quem fica no lar precisa também se ocupar do papel de quem está fora”. Dessa forma, quando há o retorno definitivo ao lar, a troca de papéis não é facilmente restabelecida. Para Aragão e colaboradores (2008), após o término da carreira, as relações se limitam ao ambiente familiar, obrigando o indivíduo a criar novos mecanismos para reinserção familiar que implica em distribuição do espaço doméstico, assim como o estabelecimento de um novo equilíbrio da dinâmica familiar. $\mathrm{O}$ retorno definitivo para casa, que já possui uma dinâmica própria, pode trazer consequências no âmbito das relações intrafamiliares.

A saúde do trabalhador vem discutindo as problemáticas das repercussões negativas na qualidade de vida com a aposentadoria. Estratégias por meio de exames médicos e psicológicos preparatórios para a aposentadoria se somam à proposição da realização de exames médicos e de saúde de natureza pós-ocupacional. Estudos mostram que exames de saúde pós-ocupacional ou pós-aposentadoria têm sido uma preocupação nas reformas dos modelos de exames de saúde, inclusive para o setor privado. (KIM; PARK; MOON, 1999) Uma das características desses exames se refere ao compromisso com a preservação da qualidade de vida após a aposentadoria. Essa perspectiva poderia ser agregada ao universo dos aposentados militares. Esses não serão descartados na aposentadoria como se faz comumente no modelo inscrito para o assalariado do setor privado. Assim, como há o compromisso pecuniário de natureza econômica que mantém a base salarial do 
militar na aposentadoria, adita-se a nova condição de dar suporte à saúde nessa fase da vida, em que se organiza o acompanhamento médico e psicossocial sistematicamente por meio de exame periódico pós-aposentadoria durante o tempo indicado para preservação da saúde física e mental do aposentado, como compromisso da instituição.

Essa pesquisa revelou que o trabalho em navios da Marinha do Brasil ocupa um importante espaço na vida dos militares e de suas famílias e que a identidade desses trabalhadores é construída a partir do pertencimento a esse grupo. Zanelli, Silva e Soares (2010) informam que a pessoa pode se considerar mais ou menos importante dependendo de seu papel profissional e do poder e prestígio de que dele advém e por meio do desempenho desses papéis as pessoas constroem suas identidades.

Desse modo, constatou-se que o momento da aposentadoria tem notável relevância para esses servidores, surgindo temores ligados ao isolamento e inutilidade. Trata-se de um momento subjetivo que envolve crenças e histórias de vidas distintas. Esse estudo reforça a importância dos projetos voltados à preparação para a reserva/aposentadoria, pois esse período de transição requer a criação de um rito de passagem para o militar e sua família, com acompanhamento de profissionais especializados como psicólogos e assistentes sociais, de modo a estimular uma transição saudável, por meio do auxílio na elaboração de projetos de vida, de modo a minimizar ou prevenir o aparecimento de dificuldades psicossociais. Além disso, os projetos associados a vivências grupais e culturais desenvolvidos para o militar que já está na reserva/aposentadoria pode estimular novas possibilidades de integração, criando condições para o participante encontrar alternativas de amizades compatíveis com seus interesses pessoais nessa fase da vida.

\section{Considerações finais}

O trabalhador militar na marinha, dotado de sua história de vida e de sua subjetividade muitas vezes encontra-se prisioneiro de um regime de efeito totalizante, sem mesmo notar. Longe da terra, da família, sua rede social mais ampla, não somente trabalha na Marinha do Brasil, porém a sua identidade se confunde com a da própria instituição. Desse modo, quando atinge o momento de "retirar a farda" e retornar ao mundo civil, encontra muitos desafios pela frente. Desafios esses que são inerentes ao confinamento e ao isolamento 
que vivenciaram durante 30 anos de serviço à nação. Entretanto, este estudo denotou expressões indicando que a magnitude temporal dessas experiências de isolamento não violou valores e princípios como da transparência e do direito de saber sobre o significado do confinamento inerente à organização do trabalho dos militares embarcados da Marinha. A natureza do confinamento dessa instituição é totalizante, porém a governança não é totalitária, o que se expressa na vontade do retorno ao mar dos marinheiros após a aposentadoria.

Esses militares, apesar da dedicação exclusiva ao serviço, ainda têm o trabalho invisível aos não conhecedores dessa realidade. Esse fato causa um espaço ainda maior entre esses dois mundos, dificultando a aproximação e o vínculo de amizades fora do ambiente institucional. Amizades duradouras são construídas em meio a adversidades dentro de um espaço cheio de regras, valores e tradições próprias. O sentido literal da palavra "servir" é contado através dos relatos de vida e das experiências das operações em alto mar.

O tempo dos militares embarcados é determinado pelas escalas de serviço, pelas comissões operativas ou pelo acionamento para os salvamentos de pessoas ou embarcações no mar. Desse modo, muitas vezes não lhe é permitido planejar viagens, participar de comemorações e eventos sociais. O sonho inicial de desbravar o oceano, com o passar dos anos é fragmentado pelo cansaço e o conflito entre o mar e a terra. Projetos são postergados e acontecimentos não são vividos dentro da contradição entre o papel do homem do mar ou do pai, marido, amigo ou filho presente.

Portanto, esse estudo trouxe contribuições no sentido de fundamentar que a hipótese apresentada para a investigação tem consonância com a realidade e que o processo de trabalho em navios operativos da Marinha do Brasil repercute na vida social de seus militares, particularmente na qualidade de vida. A pesquisa apontou ainda que esse fato pode trazer prejuízos, como a perda da identidade social, $\mathrm{o}$ isolamento e o sentimento de inutilidade num período sensível de suas vidas - a aposentadoria -, pela qual retornarão à convivência mais intensa com a família e a sociedade mais ampla. Reconhecer tais repercussões abre possibilidades para construção ou reorientação de estratégias que enfatizem a melhoria da qualidade de vida e a proteção à saúde do militar da Marinha em atividade e/ou aposentado.

Dessa forma, entende-se que a identidade desses trabalhadores militares, mediada pelo cotidiano do confinamento, se expressa contraditoriamente entre dilemas e sofrimentos vivenciados na vida profissional com saudosismo 
preservado afetivamente na memória após a aposentadoria com expressivo desejo de retorno ao mundo do trabalho. É importante compreendermos que esses militares estão inseridos em um contexto que caracteriza o trabalho como uma missão e exalta o ato de trabalhar, conferindo-lhe significância social. Esse fato traz ainda mais valor e carga afetiva para a atividade laboral.

Algumas limitações metodológicas restringiram imersões em reflexões sobre a relação entre qualidade de vida e saúde nesse estudo. Exemplifica-se não a abordagem da problemática do uso e abuso de drogas lícitas e ilícitas na vida dos embarcados. Entretanto, as riquezas empíricas observadas em relação à exploração de outras categorias analíticas permitiram conclusões contributivas com a temática no âmbito da literatura pertinente.

Assim como existem normas regulamentadoras para o trabalho confinado para os empregados pela Consolidação das Leis do Trabalho (CLT), esse estudo sustenta a importância de propostas que especifiquem e legitimem a manutenção/promoção da saúde do militar embarcado nas atividades de confinamento da marinha, considerando as peculiaridades da vida e trabalho dos "homens do mar". Acredita-se que a discussão das questões levantadas, principalmente pelos profissionais que atuam na Marinha do Brasil nos Núcleos de Assistência Integrada, com a participação dos militares e seus familiares, poderá contribuir para o planejamento, execução e aprimoramento de projetos voltados ao pessoal embarcado.

\section{Referências}

ARAGÃO, C. A. S. et al. Reserva com Qualidade. In: ENCONTRO DAS FORÇAS ARMADAS, 2., 2008, Rio de Janeiro. Anais... Rio de Janeiro, 2008.

BRASIL. Decreto $n^{\circ} 5 \cdot 417$, de 13 de abril de 2005. Aprova a Estrutura Regimental e o Quadro Demonstrativo dos Cargos em Comissão e das Funções Gratificadas do Comando da Marinha, do Ministério da Defesa, e dá outras providências. Diário Oficial [da] República Federativa do Brasil, Poder Executivo, Brasília, DF, 14 abr. 2005. Seção 1, p. 1.

BRASIL. Ministério da Marinha. Normas sobre a Assistência Integrada na Marinha do Brasil-DGPM-501. 5. rev. Rio de Janeiro: Diretoria de Assistência Social da Marinha, 2010. Mod. 2.

BRASIL. Ministério da Saúde. Resolução no 466, de 12 de dezembro de 2012. Diário Oficial [da] República Federativa do Brasil, Brasília, DF, 2012. 
BRASIL. Ministério do Trabalho e Emprego. Portaria ${ }^{\circ}$ 202, de 22 de dezembro de 2006. Aprova a Norma Regulamentadora n. 33 (NR-33), que trata de Segurança e Saúde nos Trabalhos em Espaços Confinados. Diário Oficial [da] República Federativa do Brasil, Brasília, DF, 27 dez. 20o6. Disponível em: $<$ http://acesso.mte.gov.br/data/files/FF8o8o812BE914E6012BF $3 \mathrm{EoF}_{1} \mathrm{C}_{52} \mathrm{FBD}$ /p_20061222_202.pdf >.Acesso em:25 mar. 2015.

CASTRO, C. Goffman e os militares: sobre o conceito de instituição total. Militares e Política, Rio de Janeiro, v. 1, 2007.

GOFFMAN, E. Manicômios, prisões e conventos. 2. ed. São Paulo: Perspectiva, 1987. GUIA de guerra naval. 20oo. Disponível em: <http://www.oocities.org/ guerraaeronaval>. Acesso em: 19 mar. 2014.

HALPERN, E. E.; LEITE, L. M. C. A construção do habitus alcoólico e o consumo de bebidas alcoólicas no trabalho entre pacientes militares da Marinha do Brasil. Cadernos Saúde Coletiva, Rio de Janeiro, v. 19, n. 3, p. 356-365, 2011.

HALPERN, E. E.; LEITE, L. M. C. A interseção entre os trabalhos marinheiros e o alcoolismo. Revista Psicologia: Organizações e Trabalho, Florianópolis, v. 13, n. 2, p.111-126, ago. 2013a.

HALPERN, E. E.; LEITE, L. M. C. Etilismo na jornada laboral: peculiaridades da vida naval. Saúde e Sociedade, São Paulo, v. 23, n. 1, p.131-145, jan./mar. 2014.

HALPERN, E. E.; LEITE, L. M. C. Oportunidades de beber a bordo: características do labor naval. Physis: Revista de Saúde Coletiva, Rio de Janeiro,v. 23 , n. 4, p. 1277-1296, out./dez. 2013b.

KIM, Y.; PARK, J.; MOON, Y. Special medical examination program reform proposal in Korea. Industrial Health, Japan, v. 37, n. 1, p. 109-115, 1999.

LEITE, R. M. S. C. Bandeirantes do mar: a identidade dos trabalhadores das plataformas de petróleo. Niterói: Intertexto, 2009.

LIMONGI-FRANÇA, A. C. Qualidade de vida no trabalho - QVT: conceitos e práticas nas empresas da sociedade pós-industrial. 2. ed. São Paulo: Atlas, 2004.

LINS, M. R. F. Viveiros de "homens do mar": escolas de aprendizes-marinheiros e as experiências formativas na marinha militar do Rio de Janeiro (1870-1910). 2012. 383 f. Tese (Doutorado em Políticas Públicas e Formação Humana) - Faculdade de Educação, Universidade do Estado do Rio de Janeiro, Rio de Janeiro, 2012.

MARINHA DO BRASIL. Estrutura organizacional. 2014. Disponível em: <https:// www.marinha.mil.br/content/estrutura-organizacional>. Acesso em: $1^{\circ}$ jan. 2014. MARINHA DO BRASIL. História Naval. 2013. Disponível em: <https://www. marinha.mil.br/content/historia-naval>. Acesso em: 20 dez. 2013. 
MINAYO, M. C. S. O desafio do conhecimento: pesquisa qualitativa em saúde. 12. ed. São Paulo: Hucitec, 2010. (Saúde em debate, 46).

MINAYO, M. C. S. (Org.). Pesquisa social: teoria, método e criatividade. 27. ed. Petrópolis: Vozes, 2008.

MINAYO, M. C. S.; HARTZ, Z. M. A.; BUSS, P. M. Qualidade de vida e saúde: um debate necessário. Ciência \& Saúde Coletiva, Rio de Janeiro, v. 5, n. 1, p. 7-18, 2000.

MINAYO, M. C. S.; SOUZA, E. R. (Org.). Missão investigar: entre o ideal e a realidade de ser policial. Rio de Janeiro: Garamond, 2003 .

RODRIGUES, M. et al. Preparação para a aposentadoria: o papel do psicólogo frente a essa questão. Revista Brasileira de Orientação Profissional, São Paulo, v. 6, n. 1 , p. 53-62, jun. 2005 .

SALLES, D. M. R.; COSTA, I. S. A. Representações do trabalho: estudo sobre confinamento na indústria petrolífera. Revista de Administração de Empresas, vol. 53, n.3, p. 23o-242, maio/jun. 2013. Disponível em: <http://www.scielo.br/pdf/rae/ v53n3/o2.pdf>. Acesso em: 17 mar. 2013 .

SILVA, M.; SANTANA, V. S. Ocupação e mortalidade na marinha do Brasil. Revista de Saúde Pública, São Paulo, v. 38, n. 5, out. 2004. Disponível em: <http://www.scielosp.org/scielo.php?script=sci_arttext\&pid=Soo3489102004000500014\&lng=en\&nrm=iso >. Acesso em: 1 abr. 2014 .

TAJFEL, H. Grupos humanos e categorias sociais: estudos em psicologia social. Lisboa: Livros Horizonte, 1982. Volume 2.

VALA, J. Representações sociais e percepções intergrupais. Análise Social, Lisboa, vol.32, n. 140, p.7-29, 1997. Disponível em: <http://analisesocial.ics.ul.pt/docume ntos/1221840494M6zFQ7xv9Rd55BV5.pdf>. Acesso em: 15 mar. 2105.

ZANELLI, J. C.; SILVA, N.; SOARES, D. H. P. Orientação para aposentadoria nas organizações de trabalho: construção de projetos para o pós-carreira. Porto Alegre: Artmed, 2010. 